tudes may be considerably increased if desirable, or the present standard of accuracy may be maintaine at much less cost than formerly.

The results of all triangulation in California south of the latitude of Monterey Bay are printed in the concluding appendix in full, including descriptions of stations as well as their latitudes and longitudes and the
lengths and azimuths of the lines joining them. In lengths and azimuths of the lines joining them. In
compact and convenient form there is given all the information in regard to this triangulation that is needed by an engineer or surveyor who wishes to utilize the results in controlling and checking surveys or in constructing maps or charts. The locations of more
than 1,300 points are accurately fixed by this triangula-

The report, in addition to the details of the foregoing operations and results, contains a record of a wide range of important work for which the aid of the Sur vey was sought because of the special training of its officers. The Superintendent attended the Fourteenth General Conference of the International Geodetic Association as delegate for the United States, and maintained direction of the observatories at Gaithersburg, Maryland, and Ukiah, California, supported by the International Geodetic Association for the purpose of measuring the variations of latitude; he was also detailed for duty in connection with the presentation of the case of the United States before the Alaska Boun dary Tribunal, being assisted by one of the officers of the Survey. As Commissioner of the United States he continued the work of remarking the boundary line
between the United States and Canada from the Rocky between the United States and Canada from the Rocky
Mountains westward, two of the officers of the Survey Mountains westward, two of the officers of the Survey being employed in the field; and as Commissioner of the United States in the International Delimitation Commission he inaugurated the work of marking the boundary between Alaska and Canada, one of the parties being under the direction of an assistant of the
Survey. One officer continued on duty as a member o the Mississippi River Commission. One officer having completed the field work of the survey of Mason an Dixon's line, the boundary between Maryland and Pennsylvania, was then detailed to prepare the maps and re-
port showing the results of the work. Another officer, port showing the results of the work. Another officer at the application of the municipal authorities, remained in charge of the triangulation of the Greate New York territory; and one representative of the mission, continued the survey of the natural oyster beds and reefs for the State of Louisiana.

\section{BLUEBERRY CULTURE}

IN grazing sections throughout the West an old and well-known custom is that of burning the dry grass $t$ improve the next year's pasture. Formerly the fires were allowed to spread and burn themselves out at
will, and the practice resulted in great forest destruction. Happily for the forests, the burning is now more carefully done when it is done at all, and on the whole the custom is falling into disuse. In Maine a practice of burning exists which is local to that State, is nove in character, and has nothing to do with grazing. The burning is to assist blueberry culture by causing the
bushes to sprout vigorously and clearing the ground f other growth.

About 1870 a factory for canning blueberries. was located in Maine, and as it prospered it was followed by others. In 1885 and again in 1899 similar factories and canning companies were established, until to-day blueberry raising and canning is an important industry in that State. To supply the increasing demand blueberry bush areas have been constantly enlarged, until now "blueberry barrens" cover some 2,600 acres in Hancock and Washington counties

A century ago these "blueberry barrens" were, for the most part, covered by a dense forest, chiefly of white pine and spruce. The forest was thinned by umbering the pine, and the increased amount of ligh permitted new kinds of undergrowth to get a foothold. Fire, as almost invariably happens, followed the lumlering, the rest of the original stand was destroyed, and the undergrowth was still further altered, a great variety of valueless underbrush and weeds taking possession of the ground, together with a stand of birch, popple, red maple, and other hardwood seedlings. As the fires continued to occur this hardwood growth became scrubby and was finally entirely eliminated, and the ground became a true barren, covered with a growth of blueberry bushes, sweet fern, brake, bunchberry, goldenrod, and sheep laurel. With the ground in such condition its best use is for blueberry culture. The blueberry owner divides his land into three portions; each year he picks the berries from one portion, lurns another portion, and allows the third to rest. The first year after the land is burned over the blueberry bushes sprout and grow a few inches. The second year they yield a full crop of berries. The third season the crop is small and of little value, and the
bushes reach a condition in which they can be burned most effectively.

Under this system of blueberry culture the land does not "run out" with constant use for the same crop. Where the burning has been properly done, the same
tracts have grown blueberries continuously for fifty years without showing any decrease in the yield. But if the land is burned over at the wrong time of the year, or the roots of the bushes are badly injured by fire, many years are required to restore the productive capacity of the tract. The best time for burning is when the melting snow leaves the ground wet and the
tops of the bushes dry After May 10 burning is very njurious, unless the spring is exceptionally late.
The canning companies own most of the blueberry
lands in Maine, except some small 25 or 50 acre private holdings. Pickers from company lands get cents a quart, while private owners receive about 6 to 8 cents a quart for their berries. The picking season lasts six weeks. A rapid picker makes from $\$ 4$ to $\$ 8$ a day; if he has a large family to help him it is not do make $\$ 600$ or $\$ 800$ in the six weeks.

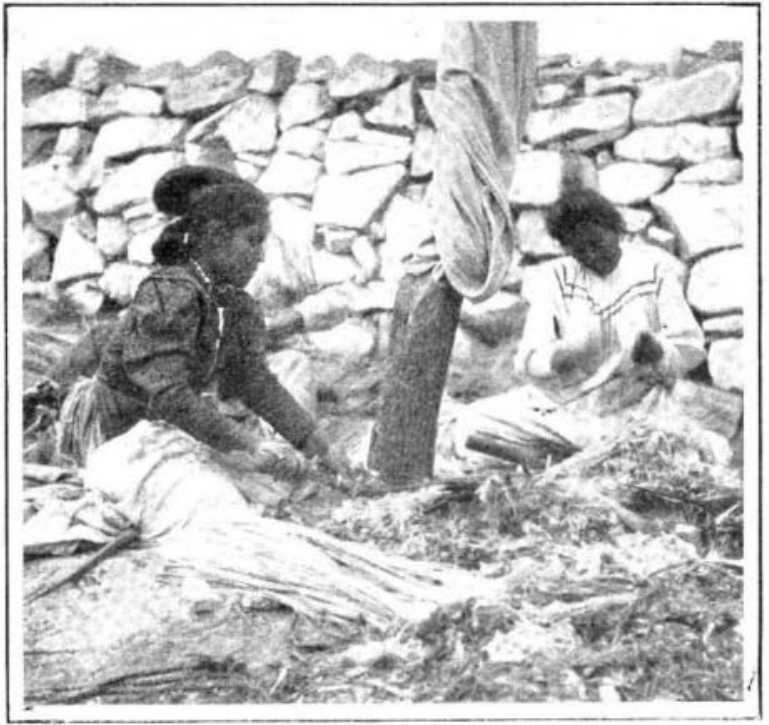

GIRLS EXTRACTIN THE FIBER.

This makes the industry very popular among the pickers, and increases the danger that forest fires will be set or permitted to burn through good timber in order to increase the extent of blueberry barrens.

In addition to the 2,600 acres of present barrens, there are in Hancock County over 5,000 acres which have been reduced almost to a barren condition. Here, if necessary, this industry could be profitably extended. But when lumbering and fires have not materially depleted the forests, the land should be continued under
forest cover and the stand improved. The opportunity forest cover and the stand improved. The opportunity
is ample for a proper extension of blueberry culture without invading valuable forest lands, which should be protected from fire. The wisest policy is to utilize the present blueberry barren areas to the fullest extent, the growth of the industry makes it profitable to take old cut-over lands for this purpose.

\section{MYSTERIOUS WHITE RACES}

$$
\text { By L. E. NeAme. }
$$

THE idea that in remote parts of the tropics, amid the dark-skinned races, there exist mysterious isolated white tribes bearing a strong resemblance to Europeans has long po:zsessed a curious fascination for the Old
World. The early adventurers in Central and Southern America brought home many tales of extraordinary cities beyond the mountains, and vague stories afloat in
South Africa thirty or forty years ago furnished Mr.

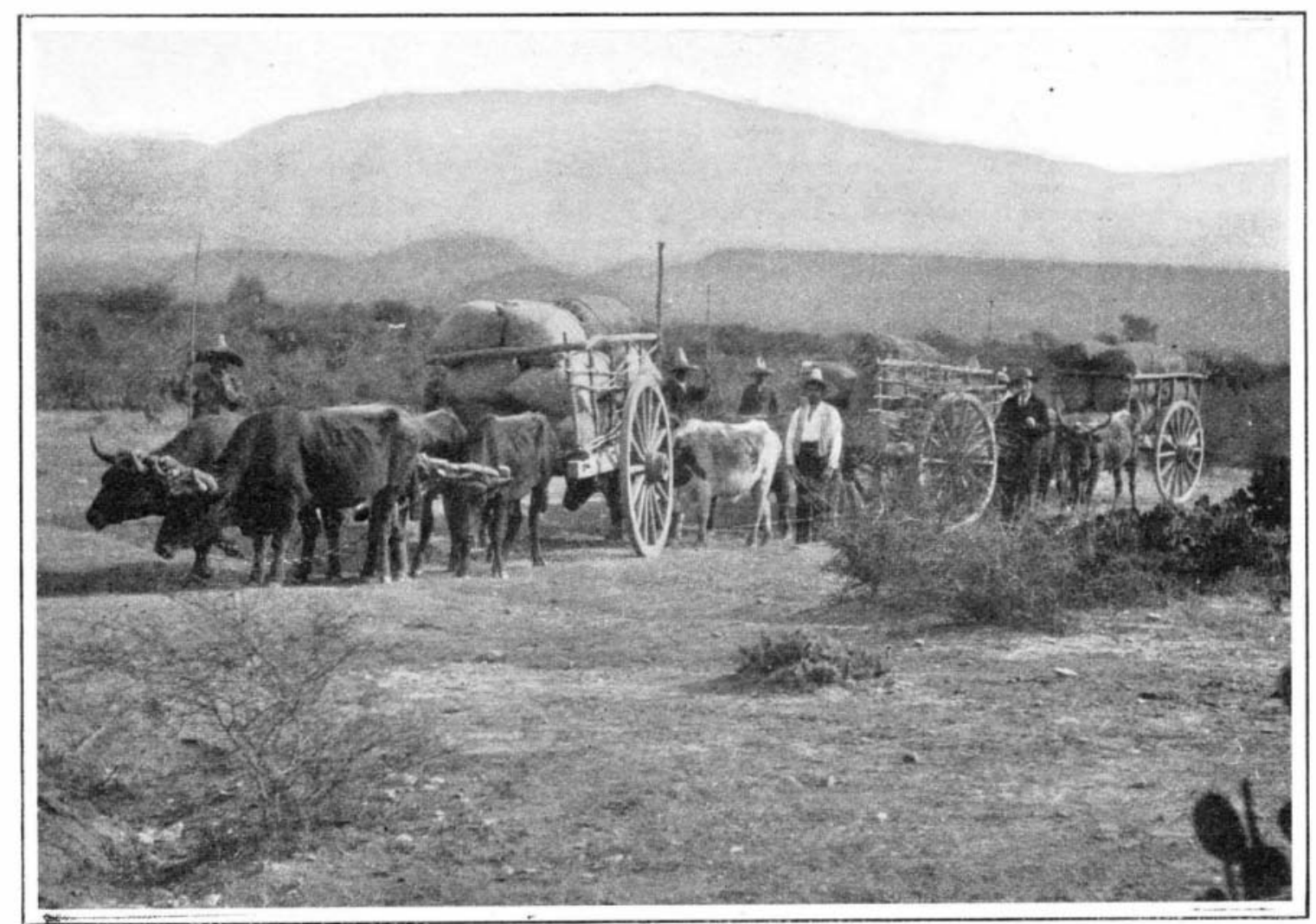

TRANSP•RTATI $\bullet$ F FIBER BY UX CARTS, NORTHEASTERN MEXIC•

THE CULTIVATION AND MANUFACTURE OF MEXICAN SUBSTITUTE CORDAGE FIBER.

Rider Haggard with a theme for one of his best-known novels, "Allan Quatermain"

Similar legends are met with in almost all the lessexplored parts of the globe, and they have always certain features in common. The isolated white peoples vague "interior" inhabit a mountainous region in a aloof from the surrounding races; they are seldom seen, and yet are definitely stated to be more civilized and better educated than the darker masses whom they avoid. Who they are and whence they came no one was thought that forgotten white explorers might have built up unknown kingdoms in the wild places of the earth. But upon examination these theories vanish a rapidy as the white tribes themselves, and the ultimate explanation is almost prosaic.

Yet so strong a hold has the idea gained that even bility of the existence of a genuine white race is not altogether scoffed at. It is less than two years ago that an American officer engaged in the operation against the Moros in the Philippines collected apparently substantial evidence relating to a mysterious white tribe in the island of Mindanao. The mountainous district in the center of this island has never been ex-
plored, and even the coast is not well known. But along the seaboard many stories are told of the fierce white people who have their home in the forest-clad mountains of the interior. Eye-witnesses depose to having seen a strange, fair-complexioned girl loiteras soon as she of a light-complexioned race are said to have been seen by more venturesome natives who were bold enough to approach the wild mountain district. The United States officer was so impressed that he determined to conduct an exploring party across the center of the vanished, for the world has as yet heard nothing of his search being crowned with success.

Arabia, however, can with more reason boast of White tribe. For years stories of such a race have been tord in the Persian Gulf, and the Rev. S. M. Zwemer, some time ago to "coffee-house babble in eastern Oman concerning a mysterious race of light-complexioned people who live somewhere in the mountains, shun strangers, and speak a language of their own." Varble; but probably the explanation is to be found in the ble, but probably the explanation is to be found in the S. B. Miles, published some time ago in the Geographical Journal. Col. Miles, in the course of his travels nearly thirty years ago, came across a town name Sheraizi in the heart of the Green Mountains. This strange place was perched like an eagle's nest on the top of a great cliff, and was inhabited by a people
of lighter skin than the rest of the tribes of the in. terior. They rarely descended to the plains, and re fused to mix or intermarry with the Arabs. Colone Miles found they were the descendants of a portion of the Persian army which invaded Oman in the tenth century. The isolation of the town and the curious behavior of its people through so many generations would undoubtedly give rise to exaggerated stories in
the bazaars on the distant coast, and in this case the the bazaars on the distant coast, and in this case the origin of the fable may be regarded as fairly certain.
Unfortunately for the romance of the world it seems Unfortunately for the romance of the world it seems have the origins novelists would wish. The world is comparatively small to-day. The trail of the explorer is over every land from Paraguay to Tibet. Forbidden ands are entered; hidden cities exist only in the imag- ination of the fictionist. In a period when trains run to Bokhara and the Great African Lakes, when the tourist appears at Khartoum, and Lhassa itself is threatened, there is no room for a mysterious white race.
Even the Dark Continent is no longer allowed to have its mysteries The photographer sits on the battered walls of Kano, the Fulani emperors have passed away. strange white people in the heart of Equatorial Africa. 
Mr. Rider Haggard's splendid race are probably only the Ba-hima originally discovere by Speke in southwestern Uganda. At least, Sir Harry Johnston claims to have discovered in them the clue to many of the mysterious white race legends found in the Dark Continent. He was engaged in nothing more thrilling than a tour of inspection to Ankole when he came across them. They are of a very light complexion, and are "aristocrats" of this region. Sir Harry John mali, or they are "obviously descended from a Gala, Somali, or other Hamitic stock," and adds that some of them are more like Egyptians than is the case with Galas and Somalis. Romance disappears before the more - The explorer. The

THE DEVELOPMENT OF THE THEORY OF ELEC TROLYTIC DISSOCIATION.*

By Prof. Svante Arrhenius, Stockholm, Sweden.

AT first sight nothing seems to be more evident than that everything has a beginning and an end, and that it is possible to divide everything. Nevertheless, the philosophers of antiquity, especially the Stoicist, concluded, on purely speculative grounds, that these opinions are not at all necessary. The wonderful development of science has reached the same conclusion a these philosophers, especially E'mpedocles and Democritus, who lived about 500 years B. C., and for whom he ancients had already a vivid admiration.

Empedocles professed that nothing is made of noth ing, and that it is impossible to annihilate anything. All that happens in the world depends upon a change of form and upon the mixture or the separation bodies. Fire, air, water, and earth are the four ele ments of which everything is composed. An everlast-

The docion is characteristic of nature.

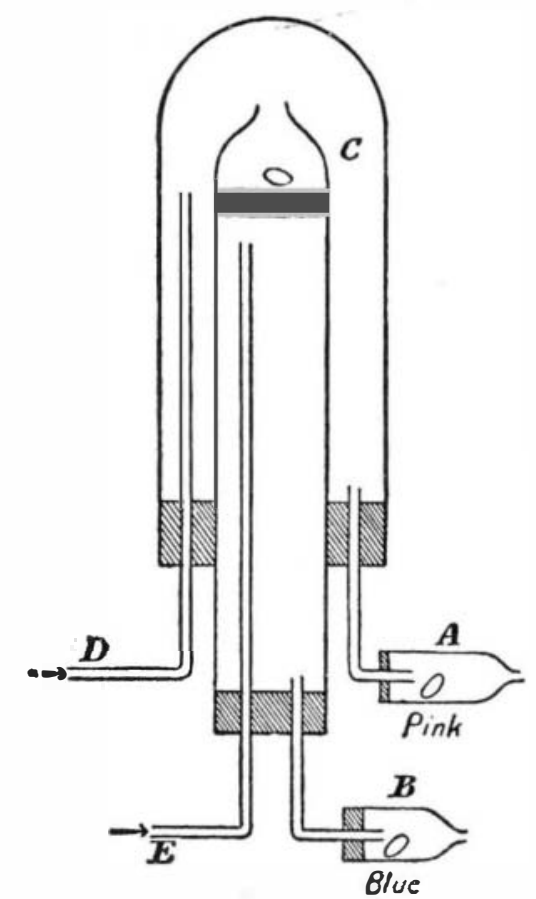

FTo. 1.

cided with our modern views. In his opinion bodie are built up of indefinitely small indivisible particles, which he called atoms. These are distinguished by their form and magnitude, and also give differe products by their different modes of aggregation. This atomic theory was revived by Gassendi abou 1650, and then accepted by Boyle and Newton. The theory received a greatly increased importance by the discovery by Dalton of the law of multiple proportions. For instance, the different combinations of nitrogen with oxygen contain, for each unit weight of nitrogen $0.57,1.14,1.72,2.29$ or 2.86 unit weights of oxygen.t pre proportion. This peculiarity is characteristic of chemstry in contradistinction to physics, where the more simple continuous and gradual transition from one tate to another prevails. This difference between the wo sister sciences has often caused controversies in the domain of physical chemistry. The occurrence of discontinuous changes and of multiple proportions has frequently been assumed, when a closer investigation has found nothing of the sort.

The law of multiple proportions is the one fundamental conception upon which modern chemistry is built up. Another is the law of Avogadro, which asserts that equal volumes of different gases under like conditions of temperature and pressure contain the same number of molecules. This conception, dating from the beginning of the nineteenth century, was at frst strongly combated, and it was its great value in explaining the new discoveries in the rapidly growing domain of organic chemistry which led to its genera acceptance in the middle of the past century, after Cannizzaro had argued strongly in its favo

There were, however, some difficulties to be removed hefore Avogadro's law could be accepted. For instance, it was found that the molecular volume of sal-am moniac, $\mathrm{NH}_{4} \mathrm{Cl}$, in the gaseous state was greater than might be expected from its chemical composition. This led to the supposition that the molecules of sal-am-

* Address before the Royal Institution of Great Britain, June 3, 1904 †To explain this we suppose, in accordance with Dalton, that the mole-
cules of the different combinations of nitrogen with oxygen contain two

moniac when in the gaseous state are partially decomposed into ammonia, $\mathrm{NH}_{3}$, and hydrochloric acid, $\mathrm{HCl}$. Indeed Von Pebal and Von Than succeeded in showing that this really happens. They used an apparatus that is shown in the annexed figure (Fig. 1). Two coaxial ubes are placed the one inside the other by means of cork. The outer tube was closed at its upper end; th inner one was open and contained at $C$ a diaphragm of a upper end was heated by an air-bath, so that the piece

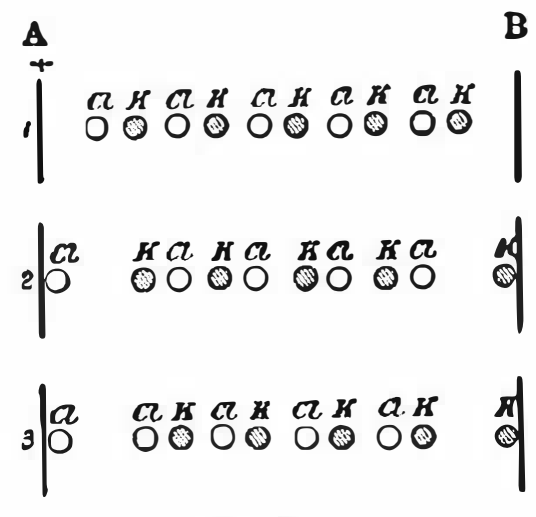

Fro. 2.

of hydrogen was led through both glass tubes $D$ and $E$. Now ammonia diffuses more rapidly than hydrochloric acid; if, therefore, the vapor of sal-ammoniac is partially decomposed into ammonia and hydrochloric acid there would be an excess of hydrochloric acid and bethere would be an excess of hydrochloric acid and be neath it an excess of ammonia. This $V$ on Pebal showe to be the caction on a pion an acid reaction on a piece of litmus-paper in $A$, an piece of litmus-paper placed in $B$. It was objected that the decomposition might possibly be caused by the the decomposition might possibly be caused by the Than, therefore, made a diaphragm of sal-ammoniac and substituted nitrogen for hydrogen, but the effect was the same.

These experiments were performed in the years 1862 and 1864. They were based on the doctrine of dissociation, which was at that time (1857) worke out by Ste. Claire-Deville, and developed by his pupils. From the most ancient times use was made of the fact that limestone at high temperatures gives off carbonic acid. and that quicklime remains. This and similar processe were studied by Ste. Claire-Deville. He found that the same law is valid for the pressure of carbonic acid over limestone and for the pressure of water vapor over liquid water at different temperatures. On these funche a thery which has subsequenty based, a theory which has subsequently playe an everincreasing role in chemistry, and whereby a broad bridge

At almost exactly the same time we find in the writins of Clausius on the conductivity of salt solution the first traces of an idea that salts or other electrolytes may be partially dissociate in aqueous solutions. Buff had found that even the most minute electric force is sufficient to drive a current through a solution of a alt. Now after the sche generally accepted, the passage of the electric current through a solution is brought about in such manner that the conducting molecules, e. g., of potassium chloride (KCI), are divided into their ions, which combine arst withe one another in the following manner: At potitive and the electrode $B$ negative. All the positive and the electrode $B$ negative. All the con-

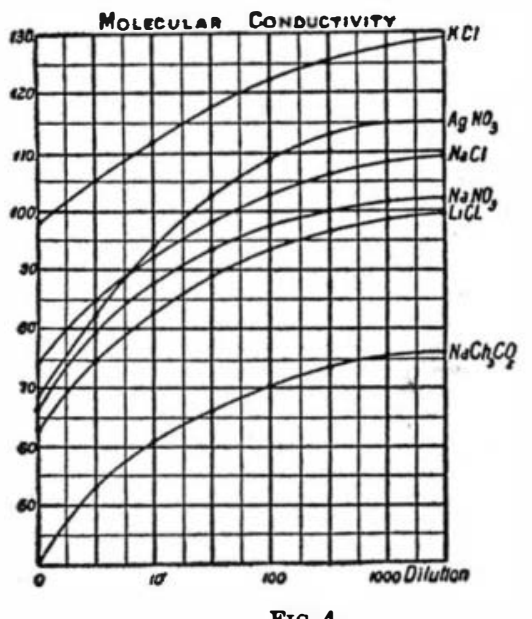

turn their positive ions $(\mathrm{K})$ to the negative electrode $B$, and their negative ions $(\mathrm{Cl})$ to the positive electrode $A$. After this, one chlorine ion is given up at $A$ and one potassium ion at $B$, and the other ions recombine, so that the $\mathrm{K}$ of the first molecule takes the $\mathrm{Cl}$ molecules turn rounde, and so on (Fig. 2). Then the tric force, so that we get the scheme 3 and a new tric force, so that we get the scheme 3 and a new de-
composition can take place. This represents the Grotthuss scheme, the place. This represents the Grotthuss scheme, that supposes continuous decor

As such exchanges of ions between the molecules take As such exchanges of ions between the molecules take motive forces, Clausius conclude that they must also take place if there is no electric force, i. e., no curren fact that William as far back 1852 in his epos maling theory of the formation of ethers, assuch an ansumed a choug free in the conception would be in good agreement with the me-

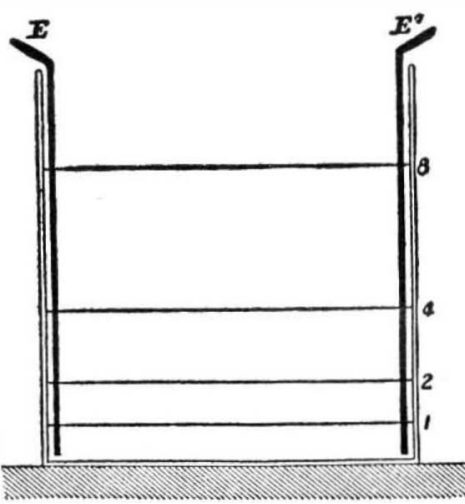

Fro. 3.

chanical theory of heat, as it was developed by Krönig,

In the meantime, Bouty, and particularly Kohlrausch worked out the methods of determining the electric onductivity of salt solutions. In 1884 I published memoir on this subject. I had found that if one ites a solution-e. g., of zinc sulphate-its conductivther molecule, or what is called its molecular conlimit. formed in the following manner (Fig. 3): In a trough with in the following manner (Fig. 3) : In a trough ith parallel walls there are placed close to two oppothe horizo plates of amalgamated layer of solution of zinc-sulphate that reaches the level 1 laye conductivity may be $k_{1}$. After this has level 1. The sond in the solution the level reaches 2 , thich after stirring the solution the level reaches 2, which lies as much ity is then found to be increative ity is then found to be increased, and to have the value $k_{2}$. Increasing in the same manner the volume by $a$ : dist rean in the previous; further the previous case say $\varkappa_{4}$. So we may proceed the end more slowly than at the beginning. but at the end more slowly than at the beginning. We appraorams, which represt the newer determinations of Kohlrausch (Figs. 4, 5)

I explaine this experiment in the following man ner: The conductivity depends upon the velocity with which the ions $\left(\mathrm{Zn}\right.$ and $\left.\mathrm{SO}_{4}\right)$ of the molecules $\left(\mathrm{ZnSO}_{4}\right)$ are carried through the liquid by the electric force, i. e., the potential difference between $E$ and $E_{1}$. If this popends only on the friction that the thens in their pare thry the liquid exert on the surrounding pascules. As thes at higer molecules, it might be expected that the conductivity would remain constant and independent of the dilution if it be suppose that all molecules, $\mathrm{ZnSO}$ dilution in the electric tranart us the electric transport. As exi riment now teaches us that the molecular conductivity increases with the distion, even if this is very high (1,000 or more molethe the hy

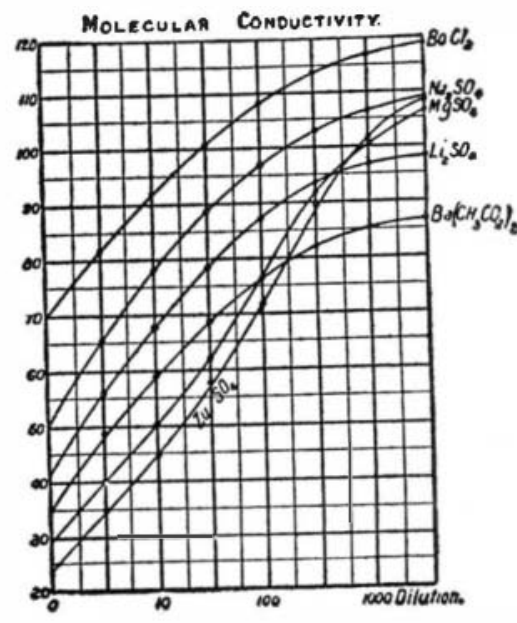

Fro.

ty. This part increases with the dilution in the same proportion as the molecular conductivity $k$. The lim iting value $k_{8}$ is approached at infinite dilution, and corresponds to the limit that all molecules conduct electricity. The conducting part of the molecules I called the active part. It may exidently be calculate as the quotient $k: k_{s}$

If now this new conception were only applicable to the explanation of the phenomena of electric conduc tivity, its value had not been so very great. But an inspection of the numbers of Kohlrausch and others for the conductivity of the acids and bases, compared with the measurements of Berthelot and Thomsen on their 